\title{
Analisis Faktor Sosiodemografi Kejadian Persalinan Preterm di RSUP Dr. Mohammad Hoesin Palembang Tahun 2019
}

\author{
Dwi Kuslimawati ${ }^{1,2 *}$, Fika Minata Wathan ${ }^{3}$, Helni Anggraini ${ }^{4}$ \\ ${ }^{1}$ Mahasiswi Program Studi D IV Kebidanan Fakultas Kebidanan dan Keperawatan, Universitas Kader Bangsa Palembang \\ ${ }^{2}$ RSUP dr. Mohammad Hoesin Palembang \\ ${ }^{3,4}$ Fakultas Kebidanan dan Keperawatan, Universitas Kader Bangsa Palembang \\ "Correspondence email: dwikuslimawati25@gmail.com
}

\begin{abstract}
Abstrak. Persalinan preterm adalah persalinan yang terjadi pada usia kehamilan kurang dari 37 minggu atau 259 hari atau kelahiran berat janin kurang dari 2.500 gram. Faktor sosiodemografi mempengaruhi terjadinya persalinan preterm. Penelitian ini bertujuan untuk mengetahui hubungan faktor sosiodemografi meliputi usia, pekerjaan, pendidikan, kebiasaan ibu merokok dan minum alkohol terhadap kejadian persalinan preterm di RSUP Dr. Mohammad Hoesin Palembang pada tahun 2019. Penelitian ini merupakan penelitian kuantitatif menggunakan desain cross sectional dengan jumlah sampel 317 responden dengan teknik systematic random sampling. Pengumpulan data dilakukan dengan melihat dan mencatat data ibu bersalin di rekam medis, pada variabel usia ibu, pekerjaan ibu, pendidikan ibu, kebiasaan merokok, kebiasaan minum alkohol dan persalinan preterm menggunakan lembar checklist yang dirancang oleh peneliti. Penelitian ini dilakukan di RSUP Dr. Mohammad Hoesin Palembang pada bulan Juli sampai Agustus 2020. Data dianalisis menggunakan uji chi square. Hasil analisis menunjukkan terdapat hubungan bermakna antara pekerjaan ibu dengan kejadian persalinan preterm ( $p$ value $=0,045<0,05)$ dengan nilai OR yaitu 0,528 , artinya ibu pekerja berpeluang 0,528 kali lebih berisiko mengalami persalinan preterm dibandingkan ibu tidak bekerja. Analisis regresi logistik sederhana menyimpulkan bahwa ibu yang bekerja mempunyai risiko untuk mengalami kejadian persalinan preterm sebesar $63,94 \%$. Dari lima faktor sosiodemografi yang diukur dalam penelitian ini, faktor pekerjaan ibu memiliki hubungan bermakna dengan kejadian persalinan preterm. Hasil ini dapat dijadikan sebagai dasar informasi tindakan promotif dan preventif terhadap kejadian persalinan preterm.
\end{abstract}

Kata kunci: Kebiasaan Merokok; Pekerjaan Ibu; Pendidikan Ibu; Persalinan Preterm; Usia Ibu

\begin{abstract}
Preterm labor is delivery that occurs less than 37 weeks or 259 days after gestation or birth weight of the fetus of less than 2,500 grams. Sociodemographic factors influence the implementation of preterm labor. This study aims to determine the relationship between sociodemographic factors including age, occupation, education, maternal smoking and alcohol habits on the incidence of preterm labor at Dr. Mohammad Hoesin Central Hospital Palembang in 2019. This research is a quantitative study using a cross sectional design with a sample size of 317 respondents with a systematic random sampling technique. Data collection was done by viewing and recording maternal data in medical records, on variables of maternal age, maternal occupation, smoking habits, drinking alcohol habits and preterm labor using a checklist designed by the researcher. This research was conducted at Dr. Mohammad Hoesin Central Hospital Palembang from July to August 2020. Data were analyzed using the chi square test. The results of the analysis showed that there was a relationship between maternal occupation and the incidence of preterm labor ( $p$ value $=0.045<0.05$ ) with an OR value of 0.528 , meaning that working mothers had a 0.528 times more risk of experiencing preterm labor than non-working mothers. Simple logistic regression analysis concluded that working mothers had a risk of experiencing preterm labor by 63,94\%. Of the five sociodemographic factors measured in this study, maternal occupational factors have a relationship between incidence of preterm labor. These results can be used as a basis for information on promotional measures and to prevent the incidence of preterm labor.
\end{abstract}

Keywords: Maternal Age; Maternal Education; Maternal Occupation; Preterm Childbirth; Smoking Habits

\section{PENDAHULUAN}

Di Indonesia kejadian persalinan preterm menduduki urutan kedua yang menyumbang sebesar $32,4 \%$ sebagai penyebab kematian Bayi Baru Lahir (BBL) pada usia 0-6 hari dan urutan keempat sebagai penyebab kematian bayi pada usia 7-28 hari yaitu sebesar 12,8\% (Kementerian Kesehatan Republik Indonesia, 2010). Persalinan preterm di Indonesia pada tahun 2010 sebesar 675.700 kasus dan mengalami penurunan pada tahun 2012 sebesar 528.000 kasus (Blencowe et al., 2012) dan pada tahun 2014 sebesar 527.672 jiwa atau $10,4 \%$ dari total kelahiran hidup di Indonesia serta menyumbang angka $3,5 \%$ terhadap seluruh persalinan preterm di dunia (Chawanpaiboon et al., 2019).

Dari 72.000 kematian neonatal pada tahun 2017, $28 \%$ disebabkan oleh kejadian intrapartum, 21,3\%, akibat gangguan respiratori dan kardiovaskular dan $19 \%$ disebabkan oleh BBLR dan kelahiran prematur (Kementerian Kesehatan Republik Indonesia, 2019). WHO dan Maternal and Child Epidemiology Estimation Group (MCEE) tahun 2019 memberikan estimasi 35\% kematian pada neonatal disebabkan oleh komplikasi persalinan preterm (Hug et al., 2019). Bayi prematur mempunyai risiko kematian 70 kali lebih tinggi, 
terutama yang lahir dengan usia kehamilan kurang dari 32 minggu (Rosyidah \& Adkhana, 2019).

Provinsi Sumatera Selatan memiliki jumlah AKN tahun 2013 sebanyak 755 kasus dan tahun 2014 menurun menjadi 629 kasus (Profil Dinas Kesehatan Provinsi Sumatera Selatan, 2015). Sedangkan tahun 2015 adalah 578 kasus, tahun 2016 berjumlah 556 dan 2017 berjumlah 540 kasus, tahun 2018 sebanyak 445 kasus (Profil Dinas Kesehatan Provinsi Sumatera Selatan, 2018). Sedangkan kematian neonatal berdasarkan Laporan Seksi Kesga Dinas Kesehatan Provinsi Sumsel tahun 2019 yaitu 422 kasus. Penyebab kematian tertinggi adalah Bayi Berat Lahir Rendah (BBLR)/bayi prematur $(48 \%)$ dan asfiksia (36\%).

Angka Kematian Neonatal (AKN) Kota Palembang pada tahun 2017 sebanyak 20 kasus dari 27.876 Kelahiran Hidup, tahun 2018 sebanyak 18 kasus dari 26.837 kelahiran hidup (Dinas Kesehatan Provinsi Sumatera Selatan, 2018). Dari Laporan Seksi Kesga Dinas Kesehatan Kota Palembang tahun 2019 AKN terdapat 15 kasus dari 24.442 Kelahiran Hidup. Penyebab kematian neonatal tertinggi yaitu asfiksia 6 kasus, BBLR/bayi prematur 5 kasus, lain-lain 3 kasus dan tetanus neonatorum 1 kasus (Dinas Kesehatan Kota Palembang, 2019).

Penelitian Wahyuni \& Rohani (2017) mendapatkan hasil usia ibu hamil memiliki hubungan dengan kejadian persalinan preterm. Usia rentang <20 tahun dan $>35$ tahun merupakan faktor risiko tinggi (Nugroho, 2012). Penelitian Carolin \& Widiastuti (2019) menunjukkan $51,7 \%$ usia berisiko mengalami persalinan preterm. Demikian pula dengan penelitian Rosyidah \& Adkhana (2019) di RSUD Panembahan Senopati Bantul menunjukkan ada hubungan usia ibu hamil dengan persalinan preterm. Studi oleh Rinata \& Anggraeni Dewi (2015) menunjukkan bahwa ibu dengan beban kerja berat mengalami kejadian persalinan preterm lebih besar dibandingkan dengan ibu dengan beban kerja ringan dengan selisih sebesar 45,8\%. Faktor tingkat pendidikan wanita signifikan mempengaruhi kejadian persalinan preterm (Sulistiarini \& Berliana, 2016). Perilaku ibu merokok lebih dari 10 batang sehari, dan minum alkohol meningkatkan risiko persalinan preterm (Rukiyah \& Yulianti, 2010).

Kejadian persalinan preterm yang terjadi di RSUP Dr. Mohammad Hoesin Palembang pada tahun 2015 ada 497 kasus persalinan preterm dari 2403 persalinan (20,7\%), tahun 2016 sebanyak $687(29,4 \%)$ dari 2340 persalinan dan tahun 2017 berjumlah 578 kasus $(26,9 \%)$ dari 2148 persalinan (Trisa et al., 2019). Tahun 2018 menjadi 604 kasus $(30,2 \%)$ dari 1998 persalinan dan 2019 menjadi 528 kasus $(34,4 \%)$ dari 1537 persalinan (Instalasi Rekam Medis dan Casemix RSMH, 2020).

Penelitian ini bertujuan untuk mengidentifikasi hubungan faktor sosiodemografi ibu yaitu usia, pekerjaan, pendidikan, serta kebiasaan ibu merokok dan minum alkohol dengan persalinan preterm.

\section{METODE}

Penelitian ini adalah penelitian kuantitatif dengan desain penelitian cross sectional, bertujuan untuk mengidentifikasi pengaruh faktor sosiodemografi ibu yaitu usia, pekerjaan, pendidikan, serta kebiasaan ibu merokok dan minum alkohol sebagai variabel independen, dengan persalinan preterm ibu sebagai variabel dependen.

Populasi dalam penelitian ini adalah data sekunder ibu yang bersalin di RSUP Dr. Mohammad Hoesin Palembang yang tercatat di Instalasi Rekam Medis dan Casemix dari Bulan Januari sampai Desember Tahun 2019 berjumlah 1537 orang. Sampel yang diambil apabila memenuhi kriteria inklusi yaitu data sosiodemografi (usia ibu, pekerjaan, pendidikan, kebiasaan merokok dan minum alkohol) terdokumentasi lengkap di rekam medik yang diambil secara systematic random sampling (acak sistematis). Sedangkan kriteria eksklusi adalah rekam medis yang tidak dapat terbaca dan tidak lengkap data sosiodemografinya. Jumlah sampel dalam penelitian ini berdasarkan perhitungan estimasi proporsi Slovin (Notoadmodjo) adalah 317,39 atau sejumlah 317 rekam medik.

Penelitian ini telah memperoleh surat keterangan lolos layak etik dari Komite Etik Penelitian Kesehatan RSUP Dr. Mohammad Hoesin Palembang dengan Nomor: 22/kepkrsmh/2020, dan persetujuan izin penelitian dari Kepala Bagian Pendidikan dan Penelitian dengan Nomor: LB.02.03/XVII.2.3/ 388/2020. Pengambilan data dilakukan selama tiga minggu pada bulan Juli sampai Agustus 2020 dengan menggunakan lembar checklist.

\section{HASIL DAN PEMBAHASAN \\ Analisis Univariat}

Hasil analisis univariat kejadian persalinan preterm tampak pada tabel 1 .

Tabel 1. Distribusi frekuensi kejadian persalinan preterm di RSUP Dr. Mohammad Hoesin Palembang Tahun 2019 $(\mathrm{n}=317)$

\begin{tabular}{lll}
\hline Persalinan Preterm & Frekuensi (f) & Persentase (\%) \\
\hline Ya & 110 & 34,7 \\
Tidak & 207 & 65,3 \\
Total & 317 & 100 \\
\hline
\end{tabular}

Tabel 1 menunjukkan lebih dari separuh persalinan di RSUP Dr. Mohammad Hoesin Palembang adalah persalinan tidak preterm $(65,3 \%)$, sedangkan persalinan preterm sebesar $34,7 \%$.

Hasil analisis univariat faktor sosiodemografi ibu tergambar pada tabel 2 . 
Dwi Kuslimawati et al, Analisis Faktor Sosiodemografi Kejadian Persalinan Preterm di RSUP Dr. Mohammad Hoesin Palembang Tahun 2019

Tabel 2. Distribusi frekuensi faktor sosiodemografi ibu di RSUP Dr. Mohammad Hoesin Palembang tahun 2019 ( $n=317)$

\begin{tabular}{|c|c|c|}
\hline Sosiodemografi & Frekuensi (f) & Persentase (\%) \\
\hline \multicolumn{3}{|l|}{ Usia } \\
\hline Risiko tinggi & 87 & 27,4 \\
\hline Risiko rendah & 230 & 72,6 \\
\hline \multicolumn{3}{|l|}{ Pekerjaan } \\
\hline Ya & 74 & 23,3 \\
\hline Tidak & 243 & 76,7 \\
\hline \multicolumn{3}{|l|}{ Pendidikan } \\
\hline Rendah & 35 & 11,0 \\
\hline Tinggi & 282 & 89,0 \\
\hline \multicolumn{3}{|l|}{ Kebiasaan Merokok } \\
\hline Ya & 0 & 0 \\
\hline Tidak & 317 & 100 \\
\hline Kebiasaan & & \\
\hline \multicolumn{3}{|l|}{ Alkohol } \\
\hline Ya & 0 & 0 \\
\hline Tidak & 317 & 100 \\
\hline
\end{tabular}

Berdasarkan tabel 2 dapat dilihat faktor sosiodemografi ibu bersalin di RSUP Dr. Mohammad Hoesin Palembang berdasarkan kelompok usia lebih dari separuh pada usia risiko rendah $(72,6 \%)$. Berdasarkan pekerjaan sebagian besar tidak bekerja (76,7\%), berdasarkan pendidikan sebagian besar pendidikan tinggi $(89,0 \%)$, berdasarkan kebiasaan merokok $100 \%$ tidak merokok, berdasarkan kebiasan minum alkohol $100 \%$ tidak minum alkohol.

\section{Analisis Bivariat}

Hasil analisis bivariat hubungan usia ibu terhadap kejadian persalinan preterm dapat dilihat pada Tabel 3.

Tabel 3. Hubungan faktor risiko usia ibu dengan kejadian persalinan preterm di RSUP Dr. Mohammad Hoesin Palembang tahun $2019(n=317)$

\begin{tabular}{|c|c|c|c|c|c|c|c|c|c|}
\hline \multirow{3}{*}{ Usia } & \multicolumn{4}{|c|}{ Preterm } & \multirow{2}{*}{\multicolumn{2}{|c|}{ Total }} & \multirow{3}{*}{$\mathbf{x}^{2}$} & \multicolumn{2}{|c|}{ OR } \\
\hline & \multicolumn{2}{|c|}{ Ya } & \multicolumn{2}{|c|}{ Tidak } & & & & & \\
\hline & $\mathbf{f}$ & $\%$ & $\mathbf{f}$ & $\%$ & $\mathbf{f}$ & $\%$ & & $(95 \% \mathrm{CI})$ & p value \\
\hline Risiko tinggi & 35 & 40,2 & 52 & 59,8 & 87 & 100 & \multirow{3}{*}{1,618} & \multirow{3}{*}{$\begin{array}{c}1,391 \\
(0,836-2,315)\end{array}$} & \multirow{3}{*}{0,254} \\
\hline Risiko rendah & 75 & 32,6 & 155 & 67,4 & 230 & 100 & & & \\
\hline Jumlah & 110 & & 207 & & 317 & & & & \\
\hline
\end{tabular}

Tabel 3 menunjukkan persentase persalinan preterm lebih tinggi pada ibu dengan usia risiko tinggi dibandingkan ibu dengan usia risiko rendah yaitu 40,2\%. Hasil uji chi square didapatkan $p$ value $>0,05$, artinya tidak terdapat hubungan yang bermakna antara usia dengan persalinan preterm. OR yang didapat yaitu 1,391, artinya ibu dengan usia risiko tinggi berpeluang 1,391 kali lebih berisiko mengalami persalinan preterm dibandingkan ibu dengan usia risiko rendah $(95 \% \mathrm{CI}$ : 0,836-2,315).

Hubungan pekerjaan ibu terhadap kejadian persainan preterm dapat dilihat pada Tabel 4.

Tabel 4. Hubungan faktor risiko pekerjaan ibu dengan kejadian persalinan preterm di RSUP Dr. Mohammad Hoesin Palembang tahun $2019(n=317)$

\begin{tabular}{|c|c|c|c|c|c|c|c|c|c|}
\hline \multirow{3}{*}{ Pekerjaan } & \multicolumn{4}{|c|}{ Preterm } & \multirow{2}{*}{\multicolumn{2}{|c|}{ Total }} & \multirow{3}{*}{$x^{2}$} & \multicolumn{2}{|c|}{ OR } \\
\hline & \multicolumn{2}{|c|}{ Ya } & \multicolumn{2}{|c|}{ Tidak } & & & & & \\
\hline & f & $\%$ & f & $\%$ & $\mathbf{F}$ & $\%$ & & $(95 \%(1)$ & $p$ value \\
\hline Ya & 18 & 24,3 & 56 & 75,7 & 74 & 100 & \multirow{3}{*}{4,587} & 0,528 & \multirow{3}{*}{0,045} \\
\hline Tidak & 92 & 37,9 & 151 & 62,1 & 243 & 100 & & $(0,292-0,953)$ & \\
\hline Jumlah & 110 & & 207 & & 317 & & & & \\
\hline
\end{tabular}

Tabel 4 menunjukkan persentase persalinan preterm lebih tinggi pada ibu yang tidak bekerja dibandingkan ibu yang bekerja yaitu $37,9 \%$. Hasil uji chi square didapatkan $p$ value $<0,05$, artinya terdapat hubungan yang bermakna antara pekerjaan dengan persalinan preterm. OR yang didapat yaitu 0,528 , artinya ibu yang bekerja berpeluang 0,528 kali lebih berisiko mengalami persalinan preterm dibandingkan ibu yang tidak bekerja (95\% CI: 0,292-0,953).

Hubungan pendidikan ibu terhadap kejadian persalinan preterm dapat dilihat pada Tabel 5 .

Tabel 5. Hubungan faktor risiko pendidikan ibu dengan kejadian persalinan preterm di RSUP Dr. Mohammad Hoesin Palembang tahun $2019(n=317)$

\begin{tabular}{|c|c|c|c|c|c|c|c|c|c|}
\hline \multirow{3}{*}{ Pendidikan } & \multicolumn{4}{|c|}{ Preterm } & \multirow{2}{*}{\multicolumn{2}{|c|}{ Total }} & \multirow{3}{*}{$\mathbf{x}^{2}$} & \multicolumn{2}{|c|}{ OR } \\
\hline & \multicolumn{2}{|c|}{ Ya } & \multicolumn{2}{|c|}{ Tidak } & & & & \multirow{2}{*}{$(95 \% \mathrm{CI})$} & \multirow{2}{*}{ p value } \\
\hline & $\mathbf{f}$ & $\%$ & & $\%$ & $\mathbf{F}$ & $\%$ & & & \\
\hline Rendah & 17 & 48,6 & 18 & 51,4 & 35 & 100 & \multirow{3}{*}{3,341} & 1,919 & \multirow{3}{*}{0,101} \\
\hline Tinggi & 93 & 33,0 & 189 & 67,0 & 282 & 100 & & $(0,946-3,895)$ & \\
\hline Jumlah & 110 & & 207 & & 317 & & & & \\
\hline
\end{tabular}


Tabel 5 menunjukkan persentase persalinan preterm lebih tinggi pada ibu yang berpendidikan rendah dibandingkan dengan ibu yang berpendidikan tinggi yaitu $48,6 \%$. Hasil uji chi square didapatkan $p$ value $>0,05$, artinya tidak terdapat hubungan yang bermakna antara pendidikan dengan persalinan preterm. OR yang didapat yaitu 1,919, artinya ibu yang pendidikan rendah berpeluang 1,919 kali lebih berisiko mengalami persalinan preterm dibandingkan ibu yang berpendidikan tinggi (95\% CI: 0,946-3,895).

Faktor risiko kebiasaan merokok tidak bisa dianalisis hubungannya dengan kejadian persalinan preterm, dikarenakan dari 317 responden ditemukan bahwa $100 \%$ responden tidak mempunyai kebiasaan merokok. Faktor risiko kebiasaan minum alkohol tidak bisa dianalisis hubungannya dengan kejadian persalinan preterm, dikarenakan dari 317 responden ditemukan bahwa $100 \%$ responden tidak mempunyai kebiasaan minum alkohol.

\section{Analisis Multivariat}

Analisisi multivariat dari variabel independen faktor sosiodemografi dan variabel dependen kejadian persalinan preterm tidak dapat dilakukan, karena dari hasil analisis bivariat hanya ditemukan satu variabel independen yang memiliki hubungan dengan variabel dependen ( $p$ value $<0,05$ ) yaitu variabel pekerjaan ibu. Dari hasil regresi logistik sederhana didapatkan ibu yang bekerja mempunyai risiko untuk mengalami kejadian persalinan preterm sebesar $63,94 \%$.

Hasil penelitian menunjukkan tidak ada hubungan bermakna antara faktor risiko usia ibu dengan kejadian persalinan preterm pada ibu ( $p$ value >0,05). Hasil penelitian ini sejalan dengan penelitian Trisa et al. (2019) di RSUP Dr. Mohammad Hoesin Palembang pada tahun 2015-2017 yang menyatakan bahwa tidak ada hubungan yang signifikan antara usia ibu dengan kejadian persalinan preterm. Hasil ini tidak sejalan dengan penelitian Rosyidah \& Adkhana (2019), Carolin \& Widiastuti (2019), penelitian Edrin et al. (2014), Sulistiarini \& Berliana (2016), dan Wahyuni \& Rohani (2017) yang menyimpulkan bahwa usia merupakan faktor yang mempengaruhi kejadian persalinan preterm. Hasil penelitian ini berbeda dengan Peneliti karena dilakukan di daerah dan Rumah Sakit yang berbeda.

Menurut WHO (2012), usia kehamilan terlalu muda dan terlalu tua merupakan risiko dari persalinan preterm. Usia ibu yang terlalu muda berkaitan dengan organ reproduksi yang belum matang secara penuh. Sedangkan ketika usia ibu >35 tahun, kesehatan ibu akan berkurang, fungsi rahim menurun dan kualitas sel telur juga menurun. Usia muda diidentikkan dengan organ reproduksi yang belum matang sedangkan usia yang terlalu tua kemampuan organ reproduksi yang menurun (Hanifah, 2017). Hasil penelitian ini menunjukkan ada $40,2 \%$ dari 87 ibu dengan usia risiko tinggi mengalami persalinan preterm, namun demikian analisis lebih lanjut menunjukkan tidak ada hubungan antara usia ibu dengan kejadian persalinan preterm.

Analisis hubungan faktor risiko pekerjaan ibu dengan kejadian persalinan preterm menunjukkan ada hubungan bermakna antara pekerjaan ibu dengan kejadia persalinan preterm ( $p$ value $<0,05)$. Hasil penelitian ini sesuai dengan penelitian yang dilakukan oleh Rinata \& Anggraeni Dewi (2015) yang menyatakan ada hubungan beban kerja pada ibu hamil dengan kejadian persalinan preterm, dan penelitian Hanifah (2017) yang menyatakan kejadian persalinan meningkat 1,3 kali lebih tinggi bila ibu hamil bekerja lebih dari 42 jam per minggu, dan bila berdiri lebih dari 6 jam sehari, dan bila tingkat kepuasan kerjanya rendah.

Pekerjaan ibu dapat meningkatkan kejadian persalinan preterm baik melalui kelelahan fisik maupun stres yang timbul akibat pekerjaannya. Kejadian persalinan preterm lebih rendah pada ibu hamil yang bukan pekerja dibandingkan dengan ibu pekerja yang hamil. Hasil analisis penelitian ini menunjukkan menunjukkan 24,3\% dari 74 ibu yang bekerja mengalami persalinan preterm. Penelitian Kajeepeta et al. (2014) menyatakan ibu dengan kelelahan tubuh berisiko 2,4 kali terhadap persalinan preterm. Selain itu ibu dengan waktu tidur $\leq 6$ jam perhari juga meningkatkan risiko persalinan preterm sebanyak 1,56 kali dibanding ibu yang tidur 7-8 jam per hari.

Analisis terhadap hubungan faktor risiko pendidikan ibu dengan kejadian persalinan preterm pada ibu menunjukkan tidak ada hubungan bermakna antara pendidikan ibu dengan kejadian persalinan preterm $(p$ value > 0,05). Hasil penelitian ini sejalan dengan penelitian Trisa et al. (2019) yang menyatakan bahwa tidak ada hubungan yang signifikan antara pendidikan ibu dengan kejadian persalinan preterm, namun penelitian ini tidak sejalan dengan penelitian Hanifah (2017) mendapatkan hasil yang berbeda, yang menyatakan bahwa ada hubungan yang bermakna antara pendidikan ibu dengan kejadian persalinan preterm. Penelitian lainnya yang dilakukan oleh Edrin et al. (2014) dan Sulistiarini \& Berliana (2016) juga menyatakan hasil yang berbeda yaitu ada pengaruh faktor pendidikan ibu dengan kejadian persalinan preterm.

Orang yang memiliki pendidikan lebih tinggi diharapkan memiliki wawasan dan pengetahuan yang lebih luas jika dibandingkan dengan orang-orang yang memiliki pendidikan yang lebih rendah. Glanz dalam Lizewski (2010) mengatakan dengan pendidikan dan pengetahuan yang baik maka individu tersebut akan memahami bahwa dia rentan dan memiliki risiko terhadap penyakit sehingga melakukan perubahan perilaku untuk mencegah hal tersebut. Pengetahuan dan kesadaran yang kurang baik dari ibu maupun pihak keluarga akan menyebabkan terjadinya kehamilan yang 
Dwi Kuslimawati et al, Analisis Faktor Sosiodemografi Kejadian Persalinan Preterm di RSUP Dr. Mohammad Hoesin Palembang Tahun 2019

berisiko, jika pengetahuan ibu baik maka ibu akan berpikir untuk menjaga kondisi kehamilan dan melakukan pencegahan agar tidak terjadi komplikasi serta perencanaan persalinan dengan baik (Kemenkes RI, 2013).

Menurut Do Carmo Leal et al. (2016), faktorfaktor penyebab persalinan preterm spontan yang berkaitan dengan aspek sosiodemografi salah satunya adalah tingkat pendidikan rendah. El-Sayed \& Galea (2012) menyatakan bahwa kejadian persalinan preterm meningkat pada ibu dengan pendidikan kurang dari 12 tahun lebih berisiko 1,73 kali dibanding ibu yang berpendidikan diploma atau derajat yang lebih tinggi. Hasil penelitian menunjukkan $48,6 \%$ dari 35 ibu dengan pendidikan rendah mengalami persalinan preterm, namun analisis lebih lanjut menunjukkan tidak ada hubungan bermakna antara pendidikan ibu dengan kejadian persalinan preterm.

Hasil analisis univariat penelitian ini menunjukkan data $100 \%$ dari 317 ibu tidak mempunyai kebiasaan merokok dan minum alkohol. Data yang homogen ini mengakibatkan tidak dapat dilakukan analisis bivariat untuk melihat hubungan antara faktor kebiasaan merokok dan minum alkohol ibu dengan kejadian persalinan preterm.

Kebiasaan merokok ibu saat hamil dapat mengganggu pertumbuhan janin dan meningkatkan risiko persalinan preterm (Moore, Blatt, Chen, Van Hook, \& Defranco, 2016). Demikian juga dengan penelitian Kondracki \& Hofferth (2019) yang menyatakan bahwa intensitas merokok tinggi dan sedang pada trimester pertama dan kedua memiliki peluang lebih tinggi untuk persalinan preterm dibandingkan intensitas merokok rendah. Pada penelitian ini tidak dapat diketahui hubungan antara kebiasaan merokok ibu dengan kejadian persalinan preterm dikarenakan tidak ada satu sampel pun yang memiliki kebiasaan merokok selama masa kehamilan.

Kebiasaan lain yang turut mempengaruhi kejadian persalinan preterm adalah minum alkohol. Alkohol adalah salah satu faktor risiko persalinan preterm dan disarankan kepada wanita untuk membatasi bahkan tidak mengkonsumsi alkohol. Konsumsi alkohol yang berat bisa meningkatkan kejadian persalinan preterm. Semakin besar konsumsi alkohol, semakin besar risikonya (Hanifah, 2017). Hasil berbeda ditunjukkan oleh penelitian Weile et al (2020) yang menyatakan bahwa tidak ada hubungan antara intake alkohol pada awal kehamilan dengan persalinan preterm spontan. Pernyataan serupa juga diperoleh dari penelitian Strandberg-Larsen et al. (2017) yang memperoleh kesimpulan bahwa minum alkohol hingga sekitar enam minuman per minggu berisiko rendah terhadap persalinan preterm. Dua hasil yang berbeda di atas tidak dapat dibuktikan dalam penelitian ini dikarenakan tidak ada satu ibu pun yang memiliki kebiasaan minum alkohol selama masa kehamilan sehingga tidak dapat diketahui ada atau tidak adanya pengaruh konsumsi alkohol terhadap persalinan preterm.

\section{SIMPULAN}

Dari hasil penelitian dan yang dilakukan pada Bulan Juli sampai Agustus Tahun 2020 di RSUP Dr. Mohammad Hoesin Palembang dapat disimpulkan:

1. Tidak ada hubungan usia ibu secara parsial dengan kejadian persalinan preterm di RSUP Dr. Mohammad Hoesin Palembang Tahun 2019 dengan $p$ value $=$ 0,254 .

2. Ada hubungan pekerjaan ibu secara parsial dengan kejadian persalinan preterm di RSUP Dr. Mohammad Hoesin Palembang Tahun 2019 dengan $p$ value = 0,045 .

3. Tidak ada hubungan pendidikan ibu secara parsial dengan kejadian persalinan preterm di RSUP Dr. Mohammad Hoesin Palembang Tahun 2019 dengan $p$ value $=0,101$.

4. Hubungan kebiasaan ibu merokok secara parsial dengan kejadian persalinan preterm di RSUP Dr. Mohammad Hoesin Palembang Tahun 2019 tidak bisa dianalisis karena data yang homogen.

5. Hubungan kebiasaan ibu minum alkohol secara parsial dengan kejadian persalinan preterm di RSUP Dr. Mohammad Hoesin Palembang Tahun 2019 tidak bisa dianalisis karena data yang homogen.

\section{DAFTAR PUSTAKA}

Carolin, B. T., \& Widiastuti, I. (2019). Faktor-Faktor Yang Berhubungan Dengan Kejadian Persalinan Preterm Di Rumah Sakit Muhammadiyah Taman Puring Kebayoran Baru Jakarta Selatan Periode (Januari-Juni) Tahun 2017. Jurnal Ilmu Keperawatan Dan Kebidanan Nasional, 1(1).

Chawanpaiboon, S., Vogel, J. P., Moller, A. B., Lumbiganon, P., Petzold, M., Hogan, D., Landoulsi, S., Jampathong, N., Kongwattanakul, K., Laopaiboon, M., Lewis, C., Rattanakanokchai, S., Teng, D. N., Thinkhamrop, J., Watananirun, K., Zhang, J., Zhou, W., \& Gülmezoglu, A. M. (2019). Global, regional, and national estimates of levels of preterm birth in 2014: a systematic review and modelling analysis. The Lancet Global Health, 7(1), e37-e46. https://doi.org/10.1016/S2214-109X(18)30451-0

Dinas Kesehatan Provinsi Sumatera Selatan. (2015). Profil Kesehatan Provinsi Sumatera Selatan Tahun 2014.

Dinas Kesehatan Propinsi Sumatera Selatan. (2019). Laporan Tahunan Seksi Kesehatan Keluarga.

Do Carmo Leal, M., Esteves-Pereira, A. P., NakamuraPereira, M., Torres, J. A., Theme-Filha, M., Domingues, R. M. S. M., Dias, M. A. B., Moreira, M. E., \& Gama, S. G. (2016). Prevalence and risk factors related to preterm birth in Brazil. 
Reproductive Health, 13(Suppl 3). https://doi.org/10.1186/s12978-016-0230-0

Edrin, V. L., Ariadi, A., \& Irawati, L. (2014). Gambaran Karakteristik Ibu Hamil pada Persalinan Preterm di RSUP Dr. M. Djamil Padang Tahun 2012. Jurnal Kesehatan Andalas, 3(3), 311-317. https://doi.org/10.25077/jka.v3i3.110

El-Sayed, A. M., \& Galea, S. (2012). Temporal changes in socioeconomic influences on health: Maternal education and preterm birth. American Journal of Public Health, 102(9), 1715-1721. https://doi.org/10.2105/AJPH.2011.300564

Hanifah, A. L. (2017). Faktor-faktor yang berhubungan dengan persalinan preterm di RSUD Wonosari tahun 2015-2016. Politeknik Kesehatan Kementerian Kesehatan Yogyakarta.

Kajeepeta, S., Sanchez, S. E., Gelaye, B., Qiu, C., Barrios, Y. V., Enquobahrie, D. A., \& Williams, M. A. (2014). Sleep duration, vital exhaustion, and odds of spontaneous preterm birth: A casecontrol study. BMC Pregnancy and Childbirth, 14(1), 1-10. https://doi.org/10.1186/1471-239314-337

Kementerian Kesehatan RI. (2012). Pedoman Penyelenggaraan PONEK 24 Jam Di Rumah Sakit. Direktorat Bina Upaya Kesehatan.

Kementerian Kesehatan Republik Indonesia. (2010). Ibu selamat, bayi sehat, suami siaga. www.depkes.go.id

Kemenkes RI. (2013). Menkes: Angka Kematian Ibu di Indonesia Mari Turunkan Segera. https://www.kemkes.go.id/article/view/2418/menk es-angka-kematian-ibu-di-indonesia-mariturunkan-segera.html

Kondracki, A. J., \& Hofferth, S. L. (2019). A gestational vulnerability window for smoking exposure and the increased risk of preterm birth: How timing and intensity of maternal smoking matter. Reproductive Health, 16(1), 1-10. https://doi.org/10.1186/s12978-019-0705-x

Lizewski, L. (2010). Health Belief Model. Wayne State University.

Moore, E., Blatt, K., Chen, A., Van Hook, J., \& Defranco, E. A. (2016). Relationship of trimesterspecific smoking patterns and risk of preterm birth. American Journal of Obstetrics and Gynecology, 215(1), 109.e1-109.e6. https://doi.org/10.1016/j.ajog.2016.01.167

Nugroho, T. (2012). Obstetri dan Ginekologi. Nuha Medika.

Rinata, E., \& Anggraeni Dewi, M. (2015). Beban Kerja Ibu Hamil Dan Kejadian Persalinan Preterm. Akademi Kebidanan Griya Husada, 2(1), 8-11. http://jurnal.akbidgriyahusada.ac.id/files/vol2no1/Penelitian2.12.pdf

Rosyidah, H., \& Adkhana, D. N. (2019). Relationship Between the Age of Pregnant Women and
Premature Labor in Panembahan Senopati Regional Public Hospital , Bantul ,. BMJ, 6(1), 20-29.

Rukiyah, A. Y., \& Yulianti, L. (2010). Asuhan Kebidanan 4 (Patologi). CV. Trans Info Media.

SDG's. (2017). Sustainable Development Goals. Strandberg-Larsen, K., Poulsen, G., Bech, B. H., Chatzi, L., Cordier, S., Dale, M. T. G., Fernandez, M., Henriksen, T. B., Jaddoe, V. W., Kogevinas, M., Kruithof, C. J., Lindhard, M. S., Magnus, P., Nohr, E. A., Richiardi, L., Rodriguez-Bernal, C. L., Rouget, F., Rusconi, F., Vrijheid, M., \& Andersen, A. M. N. (2017). Association of lightto-moderate alcohol drinking in pregnancy with preterm birth and birth weight: elucidating bias by pooling data from nine European cohorts. European Journal of Epidemiology, 32(9), 751764. https://doi.org/10.1007/s10654-017-0323-2

Sulistiarini, D., \& Berliana, M. (2016). Faktor-Faktor yang Memengaruhi Kelahiran Prematur di Indonesia: Analisis Data Riskesdas 2013. EJournal WIDYA Kesehatan Dan Lingkungan, 1(2), 109-115.

Trisa, Y., Martadiansyah, A., \& Rasyid, R. S. P. (2019). Prevalensi dan Faktor Risiko Persalinan Preterm di RSUP Dr. Mohammad Hoesin Palembang Periode 1 Januari 2015 - 31 Desember 2017. Sriwijaya Journal of Medicine, 2(2), 83-92.

Wahyuni, R., \& Rohani, S. (2017). Faktor-Faktor yang Mempengaruhi Persalinan Preterm. Jurnal Aisyah: Jurnal Ilmu Kesehatan, 2(1), 61-68. https://doi.org/10.30604/jika.v2i1.33

Weile, L. K. K., Hegaard, H. K., Wu, C., Tabor, A., Wolf, H. T., Kesmodel, U. S., Henriksen, T. B., \& Nohr, E. A. (2020). Alcohol Intake in Early Pregnancy and Spontaneous Preterm Birth: A Cohort Study. Alcoholism: Clinical and Experimental Research, 44(2), 511-521. https://doi.org/10.1111/acer.14257 